\title{
'n Plastiek Cartesiese duiker as respirometer
}

\author{
W.J. van Aardt \\ Departement Dierkunde, Potchefstroomse Universiteit vir Christelike Hoër Onderwys, \\ Potchefstroom 2520
}

Ontvang 14 Februarie 1991; aanvaar 6 Jumie 1991

\section{UITTREKSEL.}

Die werkbeginsels van die Cartesiese duiker as respirometer vir terrestriële mikro-artropode word beskryf. Die voor-en nadele van Perspex as termoplastiese duikermateriaal teenoor Pyrex- of Jena-glas word aangetoon. Met behulp van figure en fisiese afmetings word die funksionele onderdele van die Perspex-duiker, met 'n ykkonstante van ongeveer 80 mikroliters, beskryf. Aanwysings word stapsgewys verskaf, bv. hoe die duikeropstelling (flotasiehouers, manometer, glasverdeelstuk) wat in 'n spesiaal geboude waterbad gehuisves is, gebruik word om reproduseerbare metinge van die ewewigsdruk $(\Delta P)$ te maak van diere wat minder as I mg in massa is. Die berekeninge wat nodig is om die ykkonstante van elke Perspex-duiker vas te stel word uiteengesit. 'n Praktiese voorbeeld word gebruik om die suurstofverbruikerskoers (VO $\left.{ }_{2}\right)$ van 'n mytsoort vanaf die ewewigsdrukbepaling te bereken.

\section{ABSTRACT}

\section{A plastic Cartesian diver as respirometer}

The working principles of the Cartesian diver as a respirometer for terrestrial micro-athropods are discussed. The advantages and disadvantages of Perspex as thermoplastic diver material are compared with those of Pyrex or Jena glass. With the aid of diagrammes on which physical dimensions are indicated, the functional parts of a Perspex diver with a diver constant of about 80 microliters are described. Stepwise instructions for the operation of the diver system (flotation vessel, manometer, glassmanifold) within the enclosed waterbath are presented to enable one to measure the equilibrium pressure $(\Delta P)$ of each individual animal with a mass less than $1 \mathrm{mg}$. The calculations used to determine the diver constant for each diver are fully described. Practical examples are used to enable one to calculate the oxygen consumption rate $\left(\dot{V} O_{2}\right)$ for a mite species from the equilibrium pressure measurement.

\section{INLEIDING}

Sedert die eerste beskrywing ${ }^{1}$ van die Cartesiese duiker as 'n wetenskaplike instrument vir die meting van mikrohoeveelhede gasverandering vir die chemie en biologie, het die oorspronklike duikerontwerp telkens verander soos wat meer toepassings vir die duikertegniek na vore gekom het. 'n Belangrike verbetering was die aanbring van 'n hol glasproppie in die plek van die olieseël in die nek van die standaardglasduiker. ${ }^{2.3}$ Hierdie wysiging het die probleem van diffusie van gasse soos $\mathrm{CO}_{2}$ en $\mathrm{O}_{2}$ deur die olieseël grootliks beperk, aangesien slegs $5 \%$ van die duikernek se deursnitarea aan gasdiffusie blootgestel is. Nog 'n voordeel van die hol glasprop is dat die dryfbaarheid van die duiker nou hoofsaaklik bepaal word deur die afgeslote volume binne die hol prop. Die gevolg hiervan is dat 'n relatief groot massa $(0,1-0,5 \mathrm{mg})$ biologiese materiaal (ova, akwatiese mikro-artropode ens.) in die duiker geplaas kan word. Laastens, omdat die duikervolume nou kleiner is, is die duiker sensitiewer ten opsigte van sy vertikale bewegings tydens manometriese drukveranderinge. Propduikers is veral gebruik in hidrobiologiese studies waar die respirasie van baie klein akwatiese diere sowel as hulle ova vasgestel is. ${ }^{3}$

Een van die nadele van glasgemaakte duikertipes is dat dit van hoë kwaliteit glas (Pyrex, Jena) gemaak moet word. Verder vereis die metode ' $\mathrm{n}$ hoë mate van tegniese vaardigheid om die duikers te vervaardig en te yk. Hul relatiewe dun wande kan maklik breek en dit is besonder moeilik om 'n reeks glasduikers te vervaardig wat onderling dieselfde massa en digtheid besit. ${ }^{4}$

In die lig hiervan word in hierdie ondersoek 'n duiker- tipe getoets en beskryf wat van 'n termoplastiek, polimetielmetakrilaat, (handelsname: Perspex, Lucite, Plexiglass) vervaardig is. In hierdie verslag sal op die voor-en nadele van Perspex as duikermateriaal gelet word. Ook sal 'n volledige beskrywing gegee word van die praktiese aspekte van die duikertegniek soos duikervulling, yking, manometerhantering en voorbeeldberekeninge soos toegepas op die myt Anystis baccarum.

\section{MATERIAAL, METODES EN TEGNIEKE}

\section{Die werkbeginsel van 'n Cartesiese duiker}

'n Cartesiese duiker (figuur l) wat normaalweg 20 tot 30 $\mathrm{mm}$ in lengte en 2 tot $5 \mathrm{~mm}$ breed is, besit 'n reaksiekamer (a) gevolg deur 'n gasruimte (b) en 'n inskuifbare hol glasprop (c) met 'n soliede stert (d). Dit kan so gevul word met reaksievloeistof in reaksiekamer (a) en gas in gasruimte (b) dat dit vir ten minste 10 sekondes 'n neutrale dryfvermoë besit in 'n medium (e) van 'n flotasiehouer ( $f \mathfrak{l}$ ). Reaksies in reaksiekamer (a) het as resultaat dat gas óf afgegee of opgeneem kan word in die duiker se gasruimte (b). As die gas, gewoonlik suurstof, opgeneem word deur 'n organisme of weefsels in reaksiekamer (a), word verwys na respirometerduikers. As ander gasse in reaksiekamer (a) opgeneem of afgegee word, staan die duiker in diens van die biochemie of chemie. ${ }^{5}$ In hierdie verslag sal uitsluitlik aandag gegee word aan respirometerduikers.

Die Cartesiese duiker (wat volledig omring is met die flotasiemedium (e)) se gasvolume kan so aangepas wees dat die kopvlak (f) vir 10 sekondes neutraal regoor merkie 
(g) dryf. Hierdie gasvolume kan slegs noukeurig gereguleer word deur 'n drukverandering op die flotasiemedium toe te pas. As die druk bokant die flotasiemedium verhoog word, sal die volume van die gas in (b) verklein, die duiker word swaarder en sink na benede. Die verskil in die hidrostatiese druk tussen hoogte $(g)$ en $(h)$ veroorsaak dat 'n verdere druk op die gasvolume (b) uitgevoer word en die gasvolume word nog kleiner. As die duiker daarenteen op ringmerk $(\mathrm{g})$ is en die druk bokant die flotasiemedium word verlaag, sal die volume van die gas (b) vergroot en die flotasiemedium tussen die holprop en die wand van die flotasiehouer (i) verplaas word in die rigting van die flotasiemedium. Die duiker word ligter en styg boontoe in die flotasiemedium. As die druk nie weer verhoog word nie, sal die duiker al hoe vinniger boontoe styg (omdat die hidrostatiese druk ook verminder) en bokant die meniskusvlak van die flotasiemedium tot stilstand kom. Weens die oppervlakspanning en 'n te ligte duiker sal 'n verhoging in druk nie weer die duiker onder die oppervlak van die flotasiemedium laat daal nie.

Die druk wat nodig is om die duiker by merkie $(\mathrm{g})$ vir 10 sekondes te hou, word die ewewigsdruk, $\Delta \mathrm{P}$, van die duiker genoem. Die ewewigsdruk, $\Delta \mathrm{P}$, kan op 'n manometer in millimeters of sentimeters manometervloeistof afgelees word.

Die duikervergelyking. Die teoretiese grondslae van die Cartesiese mikrorespirometer is deur Linderstrom-Lang ${ }^{6}$ beskryf. Hiervolgens kan gestel word dat by die ewewigsdruk, $\Delta \mathrm{P}$, van die duiker die saamgestelde digtheid (digtheid van glas, olie, reaksiemedium) van die duiker gelyk

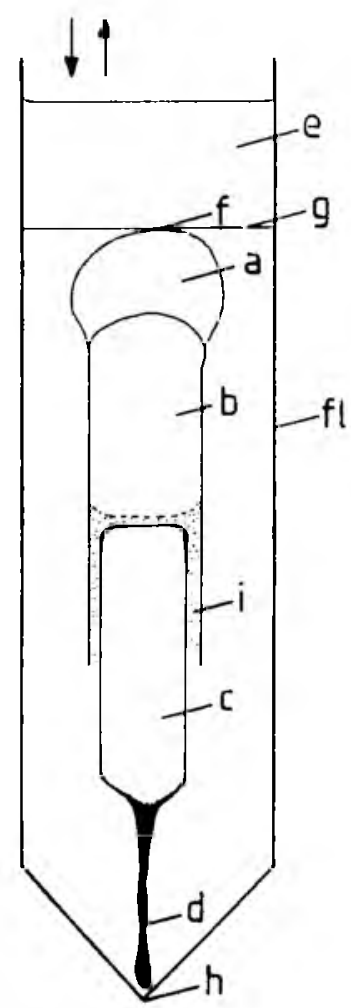

FIGUUR 1: Diagrammatiese voorstelling van 'n glaspropduiker wat in ewewigsdruk verkeer regoor merkie $(g)$ in flotasiemedium (i) van natriumhidroksied.

$a$, reaksiekamer. $b$, gasruimte. $c$, glasprop. $d$, stert. e, medium (3\% NaOH). fl, flotasiehouer. $f$, kopvlak. $g$, merkie op buitewand van flotasiehouer. $h$, bodem van flotasiehouer. $i$, ruimte tussen prop en wand van die flotasiehouer. moet wees aan die digtheid van die flotasiemedium. Vir duikers wat nie 'n olieseël of reaksiemedium besit nie, kan die vergelyking van Linderstrom-Lang ${ }^{6}$ soos volg geskryf word:

Digtheid van flotasiemedium, $\rho \mathrm{m}$,

$$
\rho \mathrm{m}=\frac{\mathrm{mD}}{\mathrm{Vg}+\frac{\mathrm{mD}}{\rho \mathrm{gl}}}
$$

waar

$\mathrm{mD}=$ massa van leë duiker,

$\mathrm{Vg}=$ volume van die duiker (duikerkonstante), $\rho \mathrm{gl}=$ digtheid van die duikermateriaal.

As die gasvolume (duikerkonstante, $\mathrm{Vg}$ ) van die duiker bereken moet word, verander die duikervergelyking van die leë duiker soos volg:

$$
\mathrm{Vg}=\frac{\mathrm{mD}-\frac{\mathrm{mD} \times \mathrm{m}}{\rho \mathrm{gl}}}{\rho \mathrm{m}}
$$

As die duiker gelaai word met byvoorbeeld 'n reaksiemengsel (X) en 'n gaasskyfie (P) word Vg kleiner, soos aangedui met die volgende vergelyking:

$$
\mathrm{Vg}=\frac{\mathrm{mD}+\mathrm{mX}+\mathrm{mP}-\left(\frac{\mathrm{mD} \times \rho \mathrm{m}}{\rho \mathrm{gl}} \frac{\mathrm{mX} \times \rho \mathrm{m}}{\rho \mathrm{ml}} \frac{\mathrm{mP} \times \mathrm{m}}{\rho \mathrm{pl}}\right)}{\rho \mathrm{m}}
$$

waar $m X=$ massa van reaksiemengsel

$\mathrm{mP}=$ massa van gaasskyfie

$\rho x l=$ digtheid van reaksiemengsel

$\rho \mathrm{pl}=$ digtheid van gaasskyfie.

Vergelyking (1) is dieselfde as $D=\frac{M}{V}$

( $\mathrm{D}=$ digtheid, $\mathrm{M}=$ massa en $\mathrm{V}=$ volume) terwyl vergelyking (2) dus dieselfde as $V=\frac{M}{\rho}$ is.

Die duikerkonstante ( $\mathrm{Vg}$ ) is die gasvolume (b) soos in fig. 1 aangetoon. Die suurstof wat deur die respirerende dier of biologiese materiaal verbruik word, is van hierdie gasvolume afkomstig. As die duikerkonstante vir die bepaalde duiker bekend is, kan die suurstofverbruikskoers, $\dot{\mathrm{VO}}_{2}$, per tydseenheid bereken word:

$$
\dot{\mathrm{V}} \mathrm{O}_{2}=\frac{\mathrm{Vg} \times \Delta \mathrm{P}}{\mathrm{P}_{0}} \times \frac{273}{\mathrm{~T}}
$$

waar $\mathrm{Vg}=$ duikerkonstante,

$\Delta \mathrm{P}=$ die verandering in ewewigsdruk in millimeters (sentimeters) per uur,

$P_{o}=$ die normale druk $(10000 \mathrm{~mm}$ Brodie of $1000 \mathrm{~cm}$ Brodie)

$\mathrm{T}=$ temperatuur in grade Kelvin.

Die duikerkonstante ( $\mathrm{Vg}$ ) hoef nie noodwendig uit berekeninge vasgestel te word nie. Met die hulp van 'n spesiale spuit' of 'n Hamilton-spuit kan 'n noukeurig afgemete volume gas in die duiker geplaas word. Hierdie metode om Vg te bepaal word hoofsaaklik by glaspropduikers toegepas ${ }^{7}$ en nie met die plastiekduiker nie. 


\section{Waterbad, manometer, verdeelstukke en termostaat} (fig. 2).

Die waterbad (Wb) met sy opklapdeksel het die volgende buite-afmetings: $35 \mathrm{~cm}$ breed, $90 \mathrm{~cm}$ lank en $60 \mathrm{~cm}$ hoog (fig. 2). As die deksel toegemaak word, is al die onderdele van die opstelling bedek. Die wande van die waterbad en deksel is van vlekvrye staal met 'n $20 \mathrm{~mm}$ polistireenbinnevoering. Die waterbad met sy deksel en polistireeninsulasie het tot gevolg dat metinge met die Cartesiese duiker nie in 'n konstante temperatuurkamer uitgevoer hoef te word nie. Nogtans is 'n termostaat (a) (Model MS, Lauda, Duitsland) nodig, wat die watertemperatuur tot $\pm 0,01^{\circ} \mathrm{C}$ noukeurig kan reguleer. Die temperatuur in die waterbad kan ook, wanncer nodig, verkoel word deur koue water deur die koperpyp (y) te sirkuleer.

Die vlekvrye staaldrom (c) besit 'n lugvolume van 3,5 liter en is met 'n vlekvrye staalpypie en 'n dikwandige rubberbuis met die regterbeen van die glasmanometer $(\mathrm{m})$ verbind. Met die drierigting glaskraan (l) kan die lug in die drom met die atmosfeer verbind word. Die manometer is vanaf die dreineerkraan (z) tot bo by kraan (l) ongeveer $1,6 \mathrm{~m}$ lank en die manometerbene bestaan uit ' $\mathrm{n}$ kapillêre glasbuis (buitedeursnee: $12 \mathrm{~mm}$; binnedeursnee: $3 \mathrm{~mm}$ ). Om die manometervloeistof ${ }^{7}(23 \mathrm{~g} \mathrm{NaCl} ; 5 \mathrm{~g}$ Natriumtaurocholaat; $500 \mathrm{ml}$ gedistileerde water; $0,1 \mathrm{~g}$ Evans-blou, $0,2 \mathrm{~g}$ timol) in die bene te laat styg of daal word ' $\mathrm{n}$ dunwandige rubberbuis (r) $2 \mathrm{~mm}$-wanddikte, $300 \mathrm{~mm}$ lank en
$15 \mathrm{~mm}$ in deursnee) en instelknoppe (p) en (q) gebruik. Die glasreservoir (n) met sy kraan (o) dien om oortollige manometervloeistof op te gaar. Die flotasiehouer $(\mathrm{g})$, glaskoppelstuk (t), dikwandige rubberbuis ( $f$ ) en eenrigtingglaskraan (d) is in totaal $40 \mathrm{~cm}$ lank en huisves die duiker $(h)$ in die flotasiemedium (v). Die lengte van die flotasichouer (met 'n slypstukgrootte 19/26) is, vanaf die horisontale ringmerk (aa) tot op die spitspunt, $7 \mathrm{~cm}$ lank en $1.7 \mathrm{~cm}$ breed. Die glasverdeelstuk (e) kan tot tien flotasiehouers dra. Die funksie van die $100 \mathrm{ml}$-spuit (u) met sy kraan ( $k$ ) en dikwandige tygonbuis (i) word gebruik om ' $n$ niedrywende duiker, soos by flotasiehouer (2), dryfbaar te maak sonder die aanvanklike gebruikmaking van die manometer. Wanneer die bopunt van die duiker egter presies regoor die ringmerk (aa) gebring moet word, word die instelknoppe (q) en (p) van die manometer gebruik. 'n Belangrike eienskap waaraan die dikwandige rubberpype en glasbuise moet voldoen, is dat die lumen van alle buise 'n klein deursnitarea moet besit. 'n Te groot totale ruimte in die buisstelsel het tot gevolg dat drukveranderinge wat geproduseer word, 'n vertraagde reaksie op die duiker uitoefen, met die gevolg dat die duiker moeilik op ringmerkvlak (aa) gebring kan word. 'n Stelsel om die glasverdeelstuk (e) en die flotasiehouers afsonderlik op of af te laat beweeg word nie in fig. 2 aangetoon nie. So 'n hystoestel vergemaklik die verwydering van die flotasiehouers uit die waterbad en duiker uit die flotasiehouer. Dit sorg ook dat

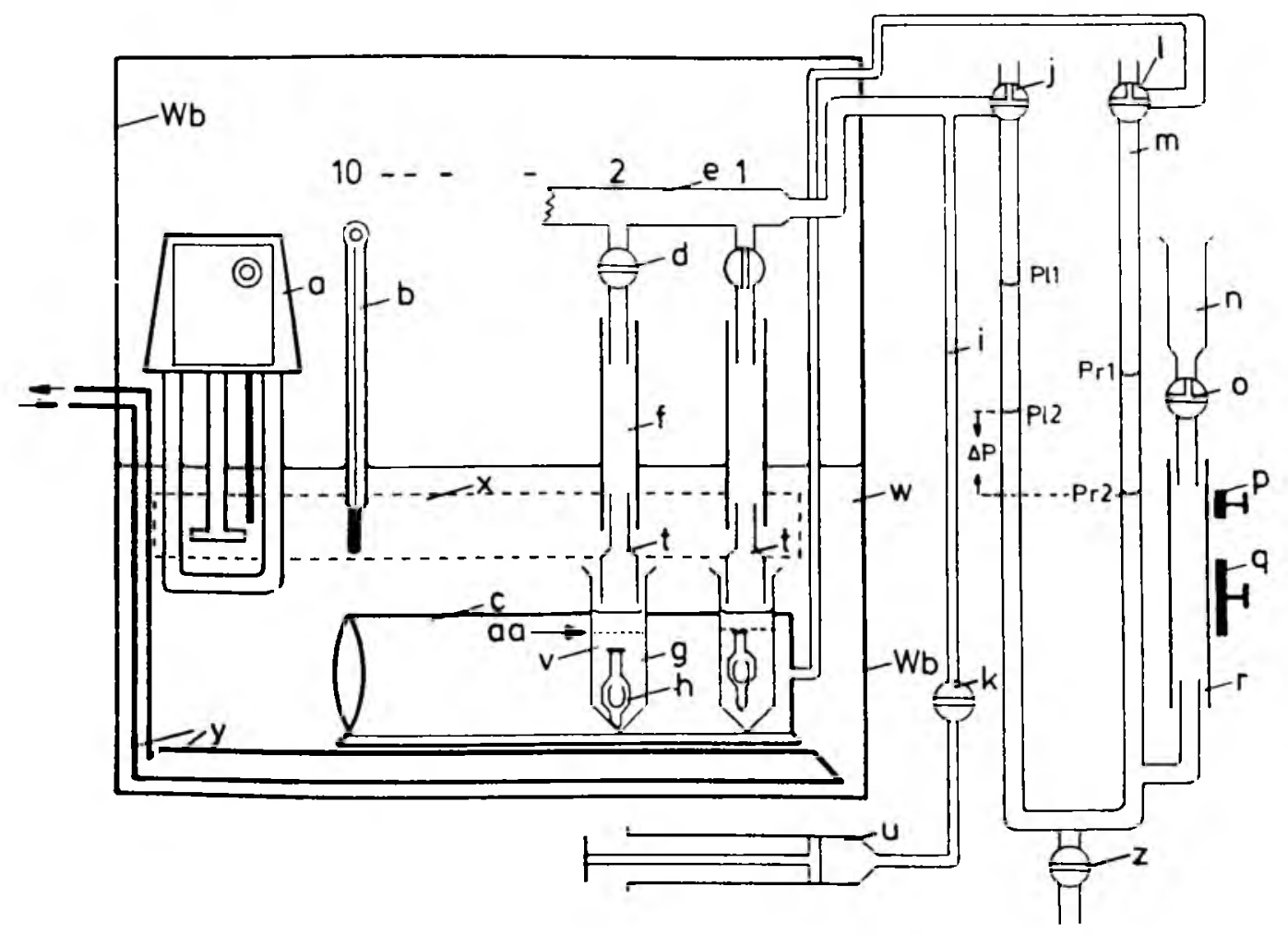

FIGUUR 2: 'n Diagrammatiese voorstelling (nie volgens skaal nie) van die waterbad, glasverdeelstukke, duikers, staaldrom en die manometeropstelling.

$a$, termostaat. $b$, termometer. $c$, staaldrom. $d$, eenrigting-glaskraan. $e$, glasverdeelstuk. $f$, dikwandige rubberbuis. g, flotasiehouer. $h$, duiker en sy posisie tussen twee metinge. $i$, dikwandige tygonbuis. $j$ en $l$, drierigtingkrane. $k$, eenrigtingkraan. $m$, glasmanometer. $n$, reservoir. o, drierigtingkraan. $p$, draaiknop vir fyner instelling. $q$, draaiknop vir growwe instelling van manometer. $r$, dunwandige rubberbuis. $t$, verdeelstukke. $u, 50 \mathrm{ml}$ spuit. v, flotasiemedium. $w$, water. $x$, ligopening op agterwand. $y$, koperpyp wat as hitte-uitruiler dien. $z$, dreineerkraan. aa, horinsontale ringmerk. Wb, waterbad.

By tyd nul is die posisie van die linker-en regterbeen van die manometer respektiewelik Pll en Prl en na 'n periode by Pl2 en Pr2. 10, tot tien flotasiehouers kan in die waterbad gehuisves word. 
die flotasiehouers met hulle verdeelstukke $(t)$ onder die wateroppervlak gebring kan word. As ligbron is 'n fluoresensiebuislig gebruik, wat buite die staalwand met sy insulasielaag gemonteer is. Aan die agterkant van die waterbad is 'n langwerpige opening $(\mathrm{x})$ deur die insulasielaag gemaak sodat die lig op die gebied van die ringmerk (aa) en die flotasiehouers skyn. Die staaldrom (c) se voetstuk is op die bodem van die waterbad met silikoonrubber vasgelym. Die voorste wand van die waterbad is van glas.

\section{Die Perspex-duiker}

Die duiker (fig. 3) bestaan uit drie aparte dele, nl. die prop (P) nek $(\mathrm{N})$ en die respirasiekamer met stertstuk (R) wat styf inmekaar pas. Tien duikers wat deur 'n instrumentmaker (Instrumentmakery, $\mathrm{PU}$ vir $\mathrm{CHO}$ ) gemaak is, besit die volgende massas (mg): 618,6, 615,0, 625,3, 618,3, 615,4, $618,1,619,0,621,0,620,1$ en 617,1 respektiewelik. Wanneer die leë duiker in ' $\mathrm{n} \mathrm{NaOH}$-oplossing met 'n soortlike digtheid van byvoorbeeld 1,0318 geplaas word, moet die duiker 'n positiewe dryfvermoë besit. As die respirasiekoers van baie aktiewe diere soos Collembola (springsterte) ondersoek word, is dit nodig om die nekgedeelte waar 'n kolom $\mathrm{NaOH}$ voorkom, af te skerm van die diere. Hiervoor word 'n ronde Perlon-gaas met 'n maasgrootte van 125 mikrometer tussen die nek en die respirasiekamer vasgeknyp.

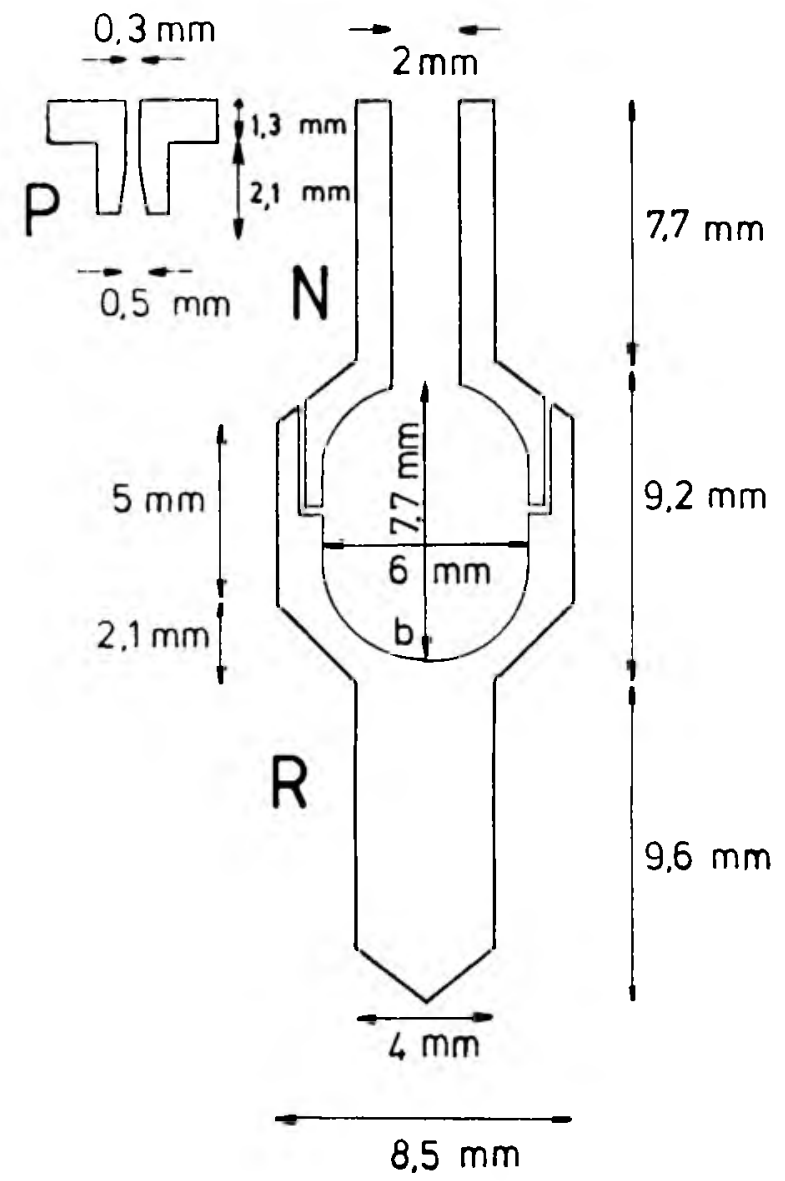

FIGUUR 3: 'n Diagrammatiese tekening van 'n Cartesiese duiker wat van Perspex gemasjineer is. Die nekgedeelte (N) word met silikoonghries aan die respirasiekamer bevestig, waar ook 'n Perlon-gaas tussen die twee dele vasgeknyp word. Die proppie $(P)$ pas stewig in die nekgedeelte $(N)$, terwyl die respirasiekamer met stertstuk $(R)$ met die hulp van silikoonghries aan die nekgedeelte bevestig word. Die massa van die leë duiker is $618,6 \mathrm{mg}$.
As die duiker gebruik word om die respirasie van enkele selle of akwatiese diere te meet moet hierdie biologiese materiaal in 'n waterige medium gedoen word. Tussen 5 - $10 \mu \mathrm{l}$ van die medium, wat op die bodem van die respirasiekamer (b) geplaas word, is hiervoor voldoende.

\section{Meetprosedure en berekeninge}

1. Die duiker word vir ten minste 24 uur voor die aanvang van die eksperiment in 'n $\mathrm{NaOH}$-oplossing gehou wat dieselfde konsentrasie en temperatuur as die $\mathrm{NaOH}$ besit wat nodig is om die flotasiehouers te vul. Hierdeur word die Perspex met water en $\mathrm{NaOH}^{\mathrm{k}}$ versadig.

2. In 'n aparte houer wat in die waterbad staan, word 'n verdere hoeveelheid $\mathrm{NaOH}$-oplossing aangehou wat met waterdampversadigde lug deurgeborrel word. ${ }^{9}$ Hierdie oplossing word gebruik om die flotasiehouers te vul.

3. Sorg dat die waterbadtemperatuur ongeveer $1^{\circ} \mathrm{C}$ tot $2^{\circ} \mathrm{C}$ laer as die kamertemperatuur is. ${ }^{7}$

4. Die waterbad moet ten minste 12 uur voor die aanvang van die metinge op die eksperimentele temperatuur gebring word.

5. Weeg die duiker en die Perlon-gaasskyfie afsonderlik tot 'n tiende van 'n milligram noukeurig. Die soortlike digtheid van die Perspex is 1,19 en dié van Perlon is $1,14{ }^{8}$ Suig 'n enkele organisme (bv. 'n myt) met die hulp van 'n Pasteur-pipet waarvan die pipet se lumen $3 \mathrm{~cm}$ van sy punt met 'n stukkie Perlon-gaasskyf versper is sodat die myt weer uitgeblaas kan word, op. Verdeel die duiker in die nek en respirasiekamergedeelte. Plaas 'n klein hoeveelheid silikoonghries op daardie deel van die nekbasis wat kontak met die vlak van die respirasiekamer maak. Blaas die myt liggies tot in die respirasiekamer en plaas die Perlongaasskyfie op, gevolg deur die nekgedeelte. Plaas die proppie op die nekgedeelte en laat die duiker versigtig in die $\mathrm{NaOH}$-oplossing vir 2 tot 3 minute dryf totdat 'n temperatuurewewig tussen die $\mathrm{NaOH}$-oplossing en duiker ingetree het (fig. 2).

6. Laai van duiker: om 'n positiewe dryfvermoë vir die duiker te verkry moet 'n bepaalde hoeveelheid $\mathrm{NaOH}$ oplossing met 'n digtheid van 1,0318 binne die nek van die duiker geplaas word (fig. 4). Om dit te bewerkstellig word die duikerstertgedeelte in die plastiekkraag (n) van 'n hipodermiese naald vasgedruk (fig. 4). Die naald word gebuig en d.m.v. sy metaalbuis op die bodem van glasbeker (b) met epoksiehars vasgegom (fig. 4). Die beker word gevul met dieselfde $\mathrm{NaOH}$-oplossing (a) wat in die flotasiehouer geplaas word, totdat die duiker daarmee bedek is (fig. 4). 'n Plastiekbuisie van $0,2 \mathrm{~mm}$ in buitedeursnee word deur die $0,3 \mathrm{~mm}$-opening van die prop tot ongeveer 3 tot $5 \mathrm{~mm}$ onder die prop se boonste vlak gesteek. Die plastiekbuisie wat van 'n Eppendorfpipetpunt gemaak is, heg lugdig aan die Luer-punt van 'n eenmilliliter wegdoenbare spuit (d) (fig. 4). Die spuit word vasgeklem aan 'n mikromanipuleerder (e) ten einde die dun gedeelte van die buisie gladweg tot op 'n bepaalde vlak in die nek van die duiker te steek (fig. 4). Die lug in die nek word onder die $\mathrm{NaOH}$-oplossing uitgesuig sodat dit met hierdie oplossing gevul raak. Sorg moet gedra word dat die $\mathrm{NaOH}$-oplossing in die nekgedeelte in verbinding is met die $\mathrm{NaOH}$-oplossing in die flotasiehouer. Met 'n skuinspunt-tangetjie word 
die duiker aan sy stertgedeelte van die plastiekkraag van die hipodermiese naald verwyder en in die $\mathrm{NaOH}$-oplossing van die beker vrygelaat.

As die duiker stadig afsak, is dit voldoende gelaai sodat dit na die flotasiehouer oorgebring kan word. As die duiker te vinnig afsak, is te veel $\mathrm{NaOH}$-oplossing in die nekgebied aanwesig en moet dit weer met die pipet weggesuig word.

7. Oordraging van die gelaaide duiker (fig. 4). Met die hulp van 'n vlekvrye staaldraad $(0,5 \mathrm{~mm}$ maat) (f) word die duiker versigtig uit die beker met $3 \% \mathrm{NaOH}$-oplossing (soortelike digtheid 1,0318) gehaal en in die flotasiemedium $(3 \% \mathrm{NaOH}$, soortelike digtheid 1,0318$)$ geplaas waar dit stadig behoort te sink, soos aangetoon deur flotasiehouer 2 (fig. 2). Sluit kraan (d) nadat die duiker in die flotasiemedium geplaas is. Die maak van 'n mikrodun plastiekbuis uit 'n geel Eppendorf-pipet: 'n Bunsen-brander met 'n pilootgasliggie word hiervoor gebruik. Steek slegs die pilootliggie aan wat met 'n geel kleur brand en waarvan die vlam nie langer as 5 tot $7 \mathrm{~mm}$ in lengte is nie. Verwarm die geel pipetpunt egalig vir

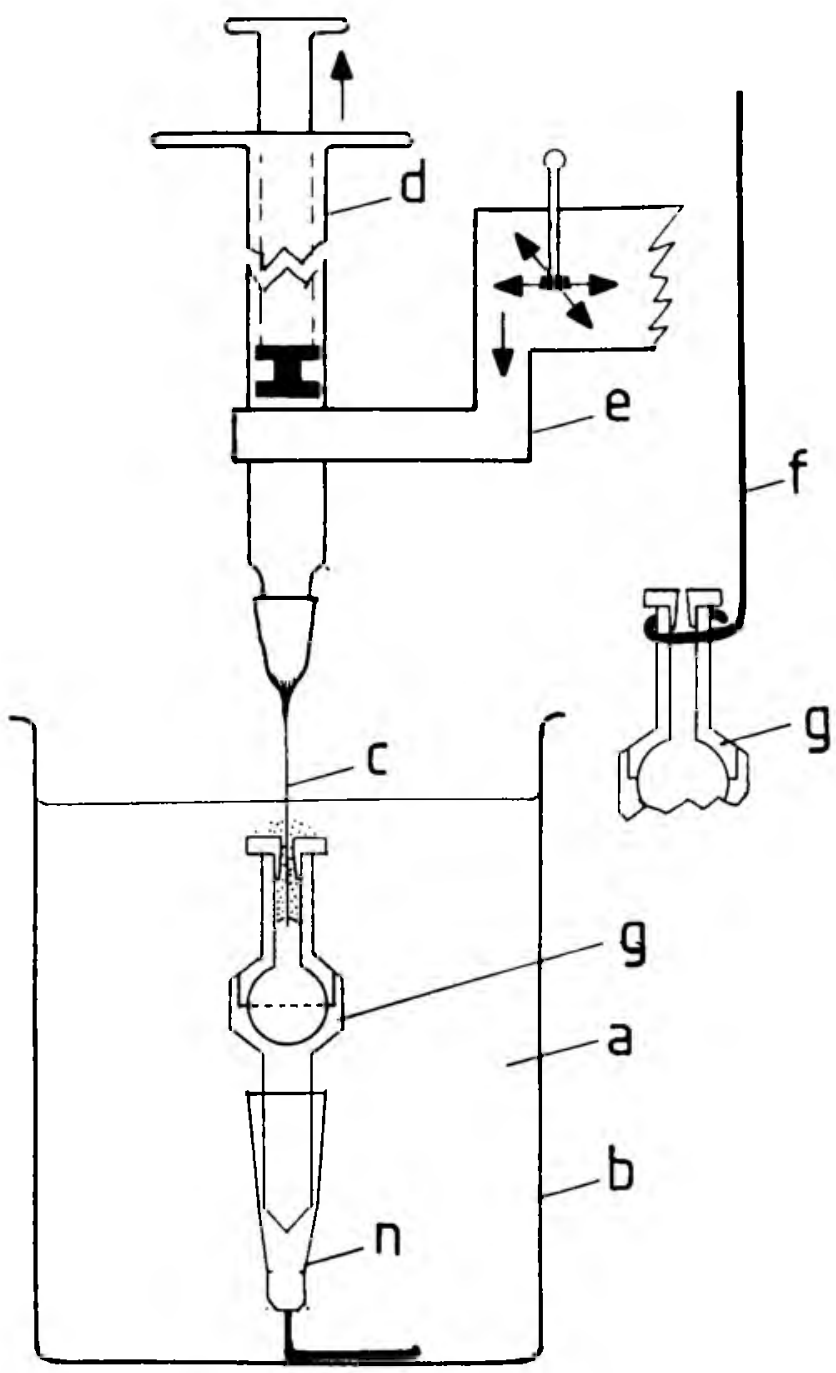

FIGUUR 4: 'n Diagrammatiese voorstelling van die tegniek om die nekgedeelte van die Cartesiese duiker met natriumhidroksied te laai.

a, 3\% NaOH-oplossing (soortelike digtheid 1,0318). b, beker. c, Eppendorf-pipetpunt wat $0,25 \mathrm{~mm}$ in buitedeursnee is. $d, I \mathrm{ml}$ plastiekspuit. $e$, gedeelte van mikromanipuleerder. $f$, vlekvrye staaldraad om die duiker uit die flotasiehouer te verwyder. $g$, duiker.
3 tot 5 sekondes, een derde vanaf die puntgedeelte, deur dit in die rondte te draai. Sodra die verhitte gedeelte sag word, moet die twee gedeeltes van die pipet vinnig uitmekaar getrek word totdat 'n fyn buisie verkry word wat ge:maklik deur die 0,3 mm-opening van die duikerprop gesteek kan word. Die pipetbuisie word lugdig aan die spuit gekoppel, wat weer op sy beurt aan die mikromanipuleerder vasgeskroef word. Met behulp van 'n handlens, handondersteuning en 'n bietjie vaardigheid (oefening) kan die duiker gevul word, selfs sonder die gebruik van 'n mikromanipuleerder.

8. Stappe in die kraan- en manometermanipulering tydens metinge.

8.1 Open die drierigtingkrane (j) en (l) vir 'n paar sekondes na die atmosfeer, asook na die staaldrom se atmosfeer.

8.2 Open kraan (d) na die flotasiehouer (2).

8.3 Open kraan (k) na spuit (u).

8.4 Bring die manometervloeistof in albei bene op die hoogste vlak.

8.5 Draai krane (j) en (l) sodat die linkermanometerbeen en die flotasiehouer (2), en die regtermanometerbeen en staaldrom (c), in verbinding is.

8.6 Laat sak die Brodie-oplossing in beide manometerbene deur skroefknop (q) antikloksgewys te draai. Indien die duiker $(\mathrm{h})$ nie vanaf die bodem van die flotasiehouer lig nie, moet spuit $(\mathrm{u})$, verbind aan tygonpyp (i), daarvoor gebruik word. Sluit kraan (k).

8.7 Sodra die duiker (h) stadig opwaarts beweeg, moet met draaiknop ( $q$ ) en draaiknop (p) (wat fyner kan instel) - die duiker vir minstens tien sekondes op ringmerk (aa) gestabiliseer word.

8.8 Noteer die lesing op die linkerbeen $\left(\mathrm{Pl}_{1}\right)$ en regterbeen $\left(\mathrm{Pr}_{1}\right)$ in millimeter of sentimeter Brodie.

8.9 Verhoog die druk in die twee manometerbene ongeveer 50 tot $60 \mathrm{~mm}$ Brodie sodat die duiker (h) afwaarts in flotasiehouer (2) beweeg.

8.10 Sluit dadelik kraan (d) van flotasiehouer (2) en noteer onmiddellik die tyd $\left(\mathrm{T}_{1}\right)$. As die respirasiekoers van die organisme in flotasiehouer (l) ook bepaal word, moet stappe 1 tot 10 herhaal word nadat die duiker op die bodem van die flotasiehouer (l) gebring is deur lading van die duiker in die beker met $\mathrm{NaOH}$-oplossing. Op hierdie manier kan die orige 8 flotasiehouers met hulle duikers in bedryf gestel word. Indien die suurstofverbruik redelik hoog is, soos wat die geval is met sekere aktiewe organismes (miere en kollembola), kan nie meer as 2 tot 3 duikers gelyktydig hanteer word nie.

8.11 Nadat die tyd van 2 minute verstreke is, word die manometerkolom van sowel regter- as linkerbeen weer na posisies $\mathrm{Pl}_{1}$ en $\operatorname{Pr}_{1}$ (fig. 2) gebring. (Gedurende hierdie tyd is krane (j) en (1) altyd in verbinding met respektiewelik die flotasiehouers/linkerbeen en die staaldrom/regterbeen, maar nie met die atmosfeer nie).

8.12 Open kraan (d) van flotasiehouer (2) en laat sak die manometervloeistof deur middel van draaiknoppe (q) en (p) totdat die duiker (h) vir 10 sekondes op die ringmerk gestabiliseer is. Neem die lesing op die linkerbeen $\left(\mathrm{Pl}_{2}\right)$ en regterbeen $\left(\mathrm{Pr}_{2}\right)$. 
8.13 Met draaiknoppe $(q)$ en (p) verhoog die druk in die manometer ongeveer met 50 tot $60 \mathrm{~mm}$ Brodie, sodat die duiker $(h)$ in die flotasiehouer (2) afwaarts beweeg.

8.14 Sluit kraan (d) van flotasiehouer (2) en noteer onmiddellik die tyd $\left(\mathrm{T}_{2}\right)$. 'n Totaal van 5 tot 10 metinge kan met ongeveer 2-minuuttydsintervalle vir elke indiwiduele organisme gemaak word. Vir groter of kleiner artropode kan die tydsintervalle korter of langer gemaak word. Die data kan grafies voorgestel word waar die ewewigsdruk teenoor die tyd uitgesit word (fig. 5) vanaf 'n tabel (tabel 1).

9. Berekeninge met praktiese voorbeelde:

Die duikerkonstante $(\mathrm{Vg})$ van elke duiker moet met vergelyking (3) bereken word.

Duiker (h): Massa van duiker $(\mathrm{mD})=618,6 \mathrm{mg}$ Digtheid van duiker $(\rho \mathrm{gl})=1,19\left(\mathrm{~g} / \mathrm{cm}^{3}\right)$ Massa van Perlon-gaas $(\mathrm{mP})=2,3 \mathrm{mg}$ Digtheid van Perlon-gaas $(\rho \mathrm{pl})=1,14\left(\mathrm{~g} / \mathrm{cm}^{3}\right)$ Digtheid van flotasiemedium $(3 \% \mathrm{NaOH}) \rho \mathrm{m}=1,0318\left(\mathrm{~g} / \mathrm{cm}^{3}\right)$

$$
\begin{aligned}
\mathrm{Vg} & =\frac{\mathrm{mD}+\mathrm{mP}-\left(\frac{\mathrm{mD} \times \rho \mathrm{m}}{\rho \mathrm{gl}}+\frac{\mathrm{mP} \times \rho \mathrm{m}}{\rho \mathrm{pl}}\right)}{\rho \mathrm{m}} \\
& =\frac{618,6+2,3-\left(\frac{618,6 \times 1,0318}{1,19}+\frac{2,3 \times 1,0318}{1,14}\right)}{1,0318} \\
& =79,91 \mu \mathrm{l}
\end{aligned}
$$

Om die suurstofverbruikskoers per uur $\left(\mathrm{V}_{2}\right)$ te bereken is dit nodig om, $\Delta \mathrm{P}$, die verandering in ewewigsdruk per minuut vas te stel. Die $\Delta P$-waarde word afgelees van die manometer as die verskil, in sentimeters Brodie, tussen die linker- en regtermanometerbeen (fig. 2). Vir 'n noukeuriger $\Delta$ P-waarde word hierdie waarde vanaf 'n grafiek afgelees (fig. 5) van waardes afkomstig uit tabel 1 . In die voorbeeld is ' $\mathrm{n}$ gemiddelde waarde van $10,5 \mathrm{~cm}$ Brodie per minuut verkry. Deur die gebruik van vergelyking (4) kan $\mathrm{VO}_{2}$ bereken word.

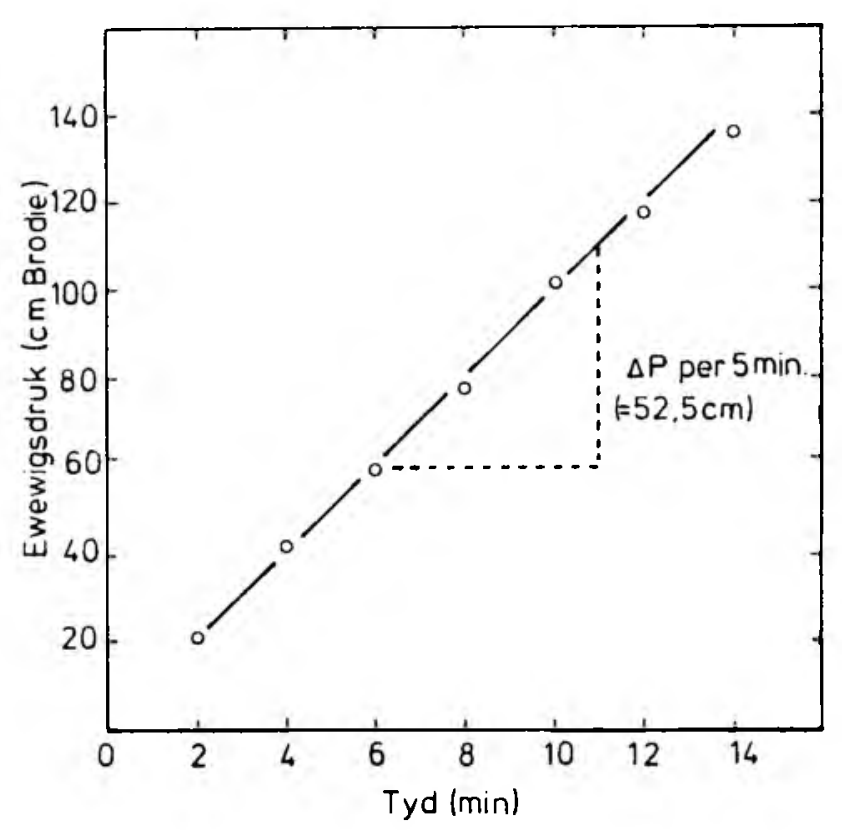

FIGUUR 5: 'n Grafiese voorstelling om die verwantskap tussen tyd en die ewewigsdruk, $\Delta P$, aan te toon. Hierdie data, verkry vanaf tabel 1 , word gebruik om die gemiddelde ewewigsdrukwaarde van 'n organisme in die duiker vas te stel.

TABEL 1

\begin{tabular}{|c|c|c|c|c|c|c|c|}
\hline \multicolumn{4}{|c|}{ NAAM VAN DIER: Anystis baccarum } & \multicolumn{4}{|c|}{ DATUM: $14 / 10 / 90$ TEMPT. $30^{\circ} \mathrm{C}$} \\
\hline \multicolumn{3}{|c|}{ Duiker nr: 4} & $\mathrm{Vg}=79,91$ & \multicolumn{3}{|c|}{ Duiker $\mathrm{nr}: 5$} & $\mathrm{Vg}=80,10$ \\
\hline \multirow{2}{*}{ TYD } & \multicolumn{2}{|c|}{ Manometerlesings } & $\Delta \mathrm{P} /$ & \multirow{2}{*}{ TYD } & \multicolumn{2}{|c|}{ Manometerlesings } & $\Delta \mathrm{P} /$ \\
\hline & Links & Regs & $2 \mathrm{~min}$. & & Links & Regs & $2 \mathrm{~min}$. \\
\hline 9:00 & 143 & 122,5 & 21,5 & $10: 00$ & 137 & 120 & 17 \\
\hline $9: 02$ & 142 & 121,5 & 21,5 & $10: 02$ & 143 & 127 & 16 \\
\hline 9:04 & 142 & 122,0 & 20,0 & $10: 04$ & 101,5 & 86 & 15,5 \\
\hline 9:06 & 142 & 123,0 & 19,0 & $10: 06$ & 103 & 88,5 & 14,5 \\
\hline 9:08 & 142 & 121,5 & 21,5 & $10: 08$ & 106 & 90 & 16 \\
\hline $9: 10$ & 142 & 127,5 & 21,5 & $10: 10$ & 111 & 96 & 15 \\
\hline $9: 12$ & 132 & 113,0 & 21,5 & $10: 12$ & 133 & 115 & 17,5 \\
\hline $9: 14$ & 132 & 113,0 & 21,5 & $10: 14$ & 130 & 114,5 & 15,5 \\
\hline \multirow{3}{*}{\multicolumn{4}{|c|}{$\begin{array}{l}\text { Berekeninge: } \\
\Delta \mathrm{P}=10,5 \mathrm{~cm} \text { per minuut } \\
\Delta \dot{\mathrm{VO}}_{2}=\frac{79,91 \times 10,5}{1000} \times \frac{273}{303}\end{array}$}} & \multirow{4}{*}{\multicolumn{4}{|c|}{ 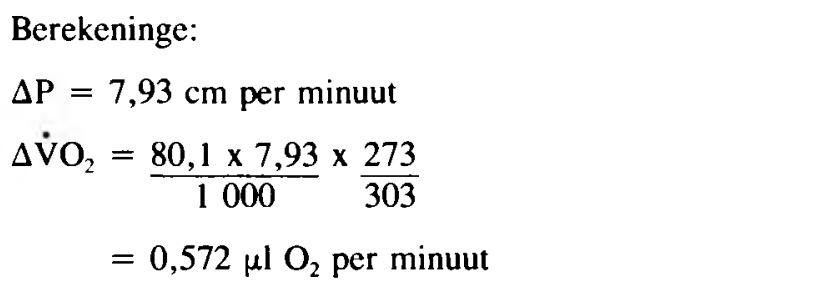 }} \\
\hline & & & & & & & \\
\hline & & & & & & & \\
\hline \multicolumn{4}{|c|}{$=0,75 \mu \mathrm{l} \mathrm{O}_{2}$ per minuut } & & & & \\
\hline
\end{tabular}

Register van eksperimentele besonderhede en metingsdata vir die berekening van die suurstofverbruikskoers ( $\left.{ } \mathrm{O}_{2}\right)$ van die mytspesie Anystis baccarum (Prostigmata) 
Vir die voorbeeld met Anystis baccarum verloop die berekeninge soos volg: (Duiker nr. 4, tabel 1)

$$
\begin{aligned}
\dot{\mathrm{VO}_{2}} & =\frac{\mathrm{Vg} \times \Delta \mathrm{P}}{\mathrm{P}_{0}} \times \frac{273}{\mathrm{~T}} \\
& =\frac{79,91 \times 10,5}{1000} \times \frac{273}{303} \\
& =0,75 \mu \mathrm{l} \text { per min. per myt } \\
& =45,3 \mu \mathrm{l} \mathrm{O}_{2} \text { per uur per myt }
\end{aligned}
$$

Indien die $\mathrm{V}_{2}$ ook per massa-eenheid uitgedruk moet word, moet ongeveer 100 myte (verkieslik almal van dieselfde ontwikkelingstadium) versamel word en in 'n ligte aluminiumhouer met dekseltjie geweeg word. Hierdeur kan die gemiddelde indiwiduele massa bepaal word.

Hoewel dit nie 'n vereiste is nie, is dit wenslik om gedurende die eksperiment 'n kontroleduiker waarin daar geen respirerende organisme is nie, vir tydsintervalle van 15 minute vir ten minste twee ure lank te meet. Enige afwykings wat deur die kontroleduiker ten opsigte van $\Delta P$ aangetoon word, kan gebruik word om die eksperimentele duikers mee te korrigeer. Kontroleduikers toon meestal geen verandering in $\Delta \mathrm{P}$ nie.

\section{BESPREKING}

Die grootste voordeel van die Perspex-duikers is dat dit maklik oopgemaak kan word. Die duikers is prakties onbreekbaar en kan vir jare diens doen. Die ontwerp van die duiker is van so 'n aard dat die suurstofverbruik van akwatiese mikro-organismes ook daarmee gemeet kan word. In so 'n geval beinvloed die water waarin die akwatiese dier hom bevind, die waarde van $\mathrm{Vg}$, die duikerkonstante. ${ }^{9}$ Indien die duikerkonstante van die leë duiker 79,91 mikroliter is en die watermedium wat in die respirasiekamer gevoeg is, bedra 10 mikroliter, sal die duikerkonstante met 10 mikroliter na 69,91 mikroliter verminder.

Soos wat dit met glaspropduikers die geval is, kan Perspex-duikers gebruik word vir die $\dot{\mathrm{VO}}_{2}$-metinge van alle organismes ${ }^{70}$ wat nie groter as $1 \mathrm{mg}$ in massa is nie. As die diere in water voorkom, moet die metinge in 'n wateromgewing plaasvind. Dan word vergelyking 3 toegepas om eers $\mathrm{Vg}$ te bepaal.

Perspex-duikers is ook gemaak (ongepubliseerde data) wat ongeveer 10 keer groter en swaarder is as die Perspexduikers wat hier beskryf word. Die duikerkonstante is ongeveer 800 mikroliter en die duiker weeg meer as 6 gram. 'n Voordeel van groot duikers is dat byvoorbeeld insekte van $5 \mathrm{mg}$ tot $10 \mathrm{mg}$ in massa hiermee gemeet kan word. Die nadeel is egter dat hierdie relatief swaar duikers nie maklik in die flotasiehouer regoor die ringmerk gestabiliseer kan word nie, o.a. weens die groot inersie van die duiker. Die suurstofverbruikskoers van insekte en ander diere groter as $10 \mathrm{mg}$ in massa kan dus nie met die Cartesiese duikertegniek bepaal word nie. In teenstelling hiermee is die Perspex-duiker wat hier beskryf word, besonder geskik om die suurstofverbruik van insekte en ander arthropode kleiner as $1 \mathrm{mg}$ in massa te meet. Omdat $\mathrm{VO}_{2}$ meting oor kort tydsintervalle van 2 minute en minder geneem kan word, kan sikliese respirasie ${ }^{\text {() }}$ by veral kleiner insekte vasgestel word. Duikers met duikerkonstantes van 10,100 en 800 mikroliter besit 'n akkuraatheid van respektiewelik $1 \times 10^{-3}, 1 \times 10^{2}$ en $1 \times 10^{-1}$ mikroliter per uur. ${ }^{5}$

Omdat Perspex se digtheid byna die helfte kleiner is as die glas wat vir glaspropduikers gebruik word, kan sterker duikers van Perspex gemaak word met groter respirasiekamers vir die meting van relatief groter diere. Die proppie wat op die nekgedeelte van die Perspex-duiker pas, dien hoofsaaklik om 'n kleiner deursnitarea van die nekgedeelte daar te stel sodat die diffusie van suurstof, of ander gasse, vanaf die respirasiekamer na die flotasiemedium, en andersom, beperk word. Die nekgedeelte kan ook makliker skoongemaak word wanneer die proppie verwyder word. Die nadeel van die Perspex-proppie is dat dit maklik kan slyt of selfs verlore kan raak.

Ten slotte kan gestel word dat die Cartesiese plastiekduiker dieselfde funksionele eienskappe as die glaspropduiker besit, met die voordeel dat die ykingsprosedure makliker uitgevoer kan word sodat dit baie tyd bespaar. Omdat die soortelike massa heelwat ligter as dié van glas is, kan swaarder diere vir $\dot{\mathrm{V}}_{2}$-metinge gebruik word. Die breekbaarheid van die Perspex-duiker is baie laer as glaspropduikers.

'n Hele aantal Perspex-duikers kan in 'n kort periode deur 'n instrumentmaker gemaak word, waarvan die eksemplare byna dieselfde massa en fisiese grootte besit. Hierdeur word tydrowende ykprosedures uitgeskakel. Dit word voorsien dat die volgende stap in die vervaardiging van plastiekduikers nie deur middel van 'n draaibank gedoen sal word nic, maar wel deur drukgieting van die termoplastiek ten einde tyd en koste te bespaar.

\section{BEDANKINGS}

Dank is verskuldig aan prof. P.D. Theron vir die identifisering van studiemateriaal en die beskikbaarstelling van literatuur, Cecile Bezuidenhout vir die voortreflike metinge, die Departement Instrumentmakery (PU vir $\mathrm{CHO}$ ) vir die vervaardiging van die duikers en die ontwerp en bou van die waterbad met toeklapdeksels, prof. dr. Els Joosse-van Damme (Vrije Universiteit, Amsterdam) vir haar aandeel in hierdie ondersoek, en prof. P. van Schalkwyk vir die korrekte gebruik van die toegepaste vergelykings.

Die finansiële steun van die SNO en die PU vir $\mathrm{CHO}$ word met dank erken.

\section{LITERATUURVERWYSINGS}

1. Linderstrom-Lang, K. (1937). Principle of the Cartesian Diver applied to gasometric technique. Naure. 140, 108.

2. Zeuthen, E. (1950). Cartesian diver respirometer, Biol. Bull, 98, 139-143.

3. Freydenberg, O. \& Zeuthen. E. (1960). Oxygen uptuke and carbon dioxide oulput related to the mitotic rhythm in the cleaving eggs of Dendraster excentric us and Urechis caupo, C.R. Lab. Carlsberg. 31. 423-455.

4. Arlian, L.G. (1973). Methods for making a Canesian diver for use with small Arthropods. Ann. Entomol. Soc. Am., 66, 694-695.

5. Holter, H. \& Linderstrom-Lang, K. (195i). Micromethods and their application in the study of enzyme distribution in the tissues of cells. Physiol. Review, 31, 423-448.

6. Linderstrom-Lang. K. (1943). On the theory of the Cartesian diver m:crorespirometer, C.R. Lab. Carlsberg, 24, 333-398.

7. Klekowski, R.Z. (1971). Cantesian diver microrespirometry for aquatic animals, Pol. Arch. Hudrobiol. 18. 93-114

8. Kohl, R. (1978). Acrylics, Machine design, 59, 108-110.

9. Holter, H. (1943). Technique of the Cartesian diver, C.R. Lab. Carlsberg, 24, 399-478.

10. Schneiderman, H.A. (1960). Discontinuous respiration in insects: role of the spiracles, Biol. Bull., 119, 494-528. 